\title{
Salvage Total Hip Replacement after Failed Internal Fixation of Trochanteric Fracture Femur
}

\author{
Mohammed a Elhenawy \\ Faculty of Medicine, Zagazig University, Egypt. \\ yousufmmkh@gmail.com
}

\begin{abstract}
Background: Total hip replacement (THR) is one treatment option for failed hip fracture fixation. It is considered as a salvage procedure for older patients, patients with poor bone stock, avascular necrosis of the femoral head, associated with damaged acetabular articular cartilage.

Patients and Methods: Total hip replacement was done for forty patients with failed internal fixation of trochanteric femoral fractures, 28 males and 12 females completed the follow up and six patients were lost. The procedure was carried out through a lateral exposure in all cases. Harris hip score (HHS) was used for clinical evaluation preoperatively, postoperatively. Radiographic evaluation comprising anteroposterior radiographic views of the pelvis and femur and a lateral view of the femur were performed at follow-up visits.

Results: The mean time of follow up was 48 months (range from 36-72 months). The mean Harris hip score was improved from a mean of 24 points preoperative to 88 points at final follow up. Pain relief and gait correction were noted at the final follow up. Twenty eight patients (70\%) could freely walk outdoors using a cane or elbow crutch; eight patients (20\%) had a limited walking ability using two axillary crutches, and four patients (10 \%) were able to walk indoors only.

Conclusion: Total hip arthroplasty is a good salvage procedure after failed internal fixation of trochanteric femoral fractures. Individual selection of the implant depends upon the age of patient, level of activity, the bone stock of proximal femur, and the condition of the acetabulum. To maintain stability, reattachment of the greater trochanter should be done. To avoid intraoperative fractures of osteoporotic bone, dislocation of the hip should be very careful.
\end{abstract}

Keywords: total hip, replacement, trochanteric fracture, failure of fixation.

\section{INTRODUCTION}

Stable trochanteric femoral fractures can be treated by internal fixation methods with union rates as high as $100 \%$ when optimal implant and good reduction have been achieved. Failure rates have been reported in literature due to comminution, osteoporosis and suboptimal fixation [1]. Functional disability and pain are the end result of failed fixation of trochanteric femoral fractures. Failure rates may be due to failure of the device (3\% - 12\%); device penetration in (2\% and $12 \%)$, nonunion $(2-5 \%)$ and malunion with varus deformity in (5-11\%). Certain unstable fracture patterns have been reported to have failure rates as high as 56\% [2-6]. Revision of internal fixation for nonunited trochanteric fractures of the femur has been reported to have good results in younger patients with good bone stock [6-10].

Total hip replacement (THR) is one treatment option for failed hip fracture fixation. It is considered as a salvage procedure for older patients, patients with poor bone stock, avascular necrosis of the femoral head, associated with damaged acetabular articular cartilage [7]. The cause of symptoms and the reason for failure 
Salvage Total Hip Replacement after Failed Internal Fixation of Trochanteric Fracture Femur

include infection, malunion, nonunion, femoral head osteonecrosis, and progressive degenerative arthritis due to internal fixation failure.There are many technical difficulties during conversion hip arthroplasty such as extraction of implants, bone deformity, bone loss, poor bone quality and associated trochanteric nonunion [11- 13].

The aim of this work was to evaluate the early results of total hip arthroplasty in a group of patients with failed internal fixation of trochanteric femoral fractures including the clinical and radiological results.

\section{Patients And Methods}

From January 2009 to December 2017, forty patients with failed internal fixation of trochanteric femoral fractures were treated by total hip replacement as a salvage procedure. The study started by 46 patients but only forty patients were available at the end of follow up. The mean age of the patients was 50 years (range: 42-66 years) and the sex distribution was 28 males and 12 females (Table 1).The type of fracture was intertrochanteric in 30 patients and subtrochanteric in 10 patients. The failed implants used inprimary fractures treatment were: Dynamic hip screw in (DHS: 31 cases), proximal femoral nail in (PFN: 6 cases), dynamic condylar screw in (DCS: 3 cases). The mean time from primary fixation to the salvage arthroplasty was 28 months (range, 12 to 34 months).

\begin{tabular}{|l|l|}
\hline Table1. All patients data preoperative & $50(42-66)$ years \\
\hline Mean Age (range) & Male: 28 \\
\cline { 2 - 2 } & Female: 12 \\
\hline \multirow{2}{*}{ Side affected } & Right: 15 \\
\cline { 2 - 2 } & Left: 25 \\
\hline \multirow{2}{*}{ Implant in first operation } & *DHS: 31 \\
\cline { 2 - 2 } & **PFN:6 \\
\cline { 2 - 2 } & ***DCS: 3 \\
\hline Mean duration between first operation and salvage & 28(12-34) months \\
\hline \multirow{2}{*}{ Type of prosthesis (fixation method) } & Cement less: 32 \\
\cline { 2 - 2 } & Cemented: 4 \\
\cline { 2 - 2 } & Hybrid: 4 \\
\hline \multirow{2}{*}{ Stem used } & Standard stem: 32 \\
\cline { 2 - 2 } & Long stem: 8 \\
\hline *(dynamic hip screw) ${ }^{* *}$ (proximal femoral nail) ***(dynamic condylar screw) \\
\hline
\end{tabular}

Intraoperative cultures were positive in 8 patients and no growth of organisms in thirty two patients. Two stages procedure was used in 8 infected cases (Figure 1), and one stage revision was done in 32 cases (Figure 2).The inclusion criteria of patients included in this study were either one or a combination of nonunion, loss of fixation, avascular necrosis of the femoral head, screw penetration of the acetabulum, chondrolysis or hip incongruity. 


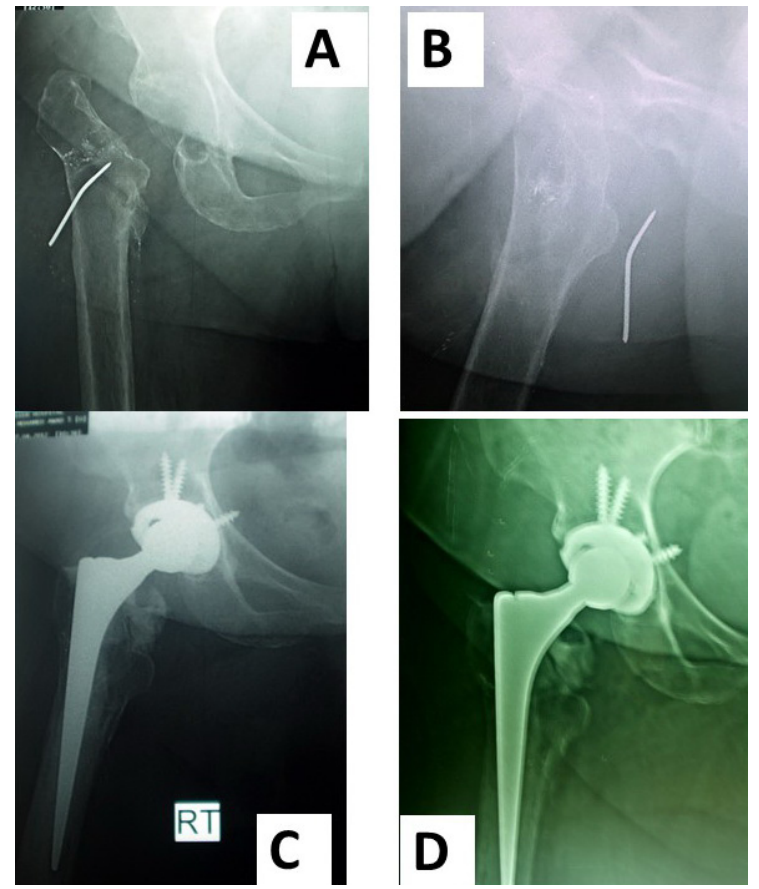

Fig1. Female patient 54 years old (Case No. 22): A\&B) preoperative $x$-ray 1 year after debridement and implant extraction due to infection; $\boldsymbol{C}$ ) postoperative $\mathrm{x}$-ray with hybrid THR (cementless cup and cemented stem); D) 3 years postoperative $x$-ray.

Bipolar prosthesis was used in patients with implant failure but normal acetabulum, and those cases were excluded, also cases with active infection not done until debridement and cure of infection at least nine months after skin closure without sinuses then second stage was done for them after laboratory investigations to ensure no microbial activity.

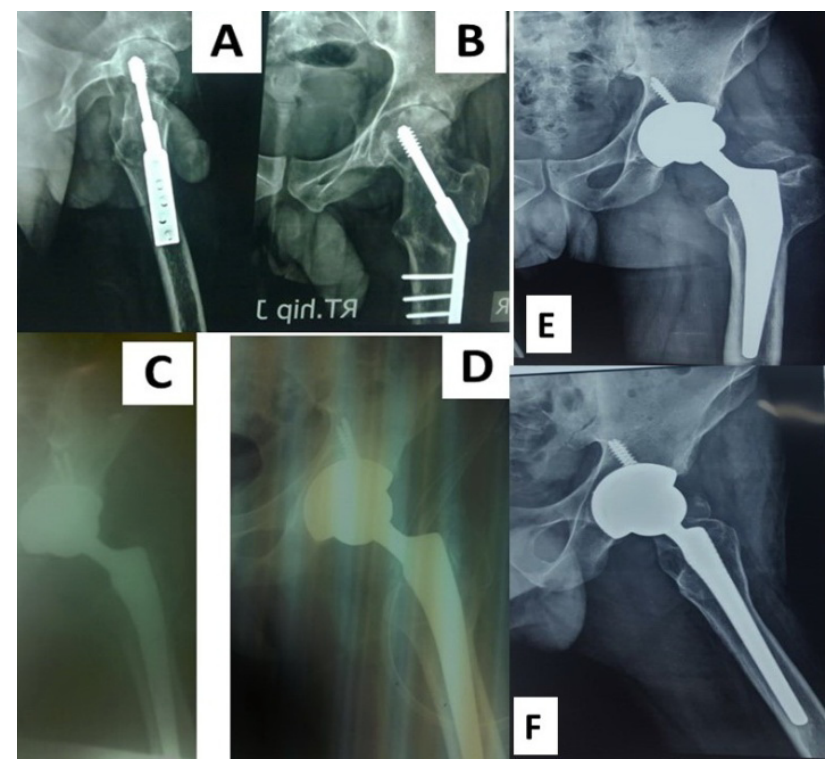

Fig2. Male patient 65 years old (Case No. 9): A\&B) preoperative $x$-ray with hip posttraumatic degeneration, C\&D) postoperative $x$-ray (cementless THR); E \&F) 4 years postoperative. 
The implant type used was Hybrid prosthesis in 4 hips (Cementless cup and cemented stem), cementless prosthesis was used in 32 hips, and cemented prosthesis in 4 hips. A $28 \mathrm{~mm}$ metal head was used in 30 cases, $32 \mathrm{~mm}$ metal head in 10 cases (Fig 3).

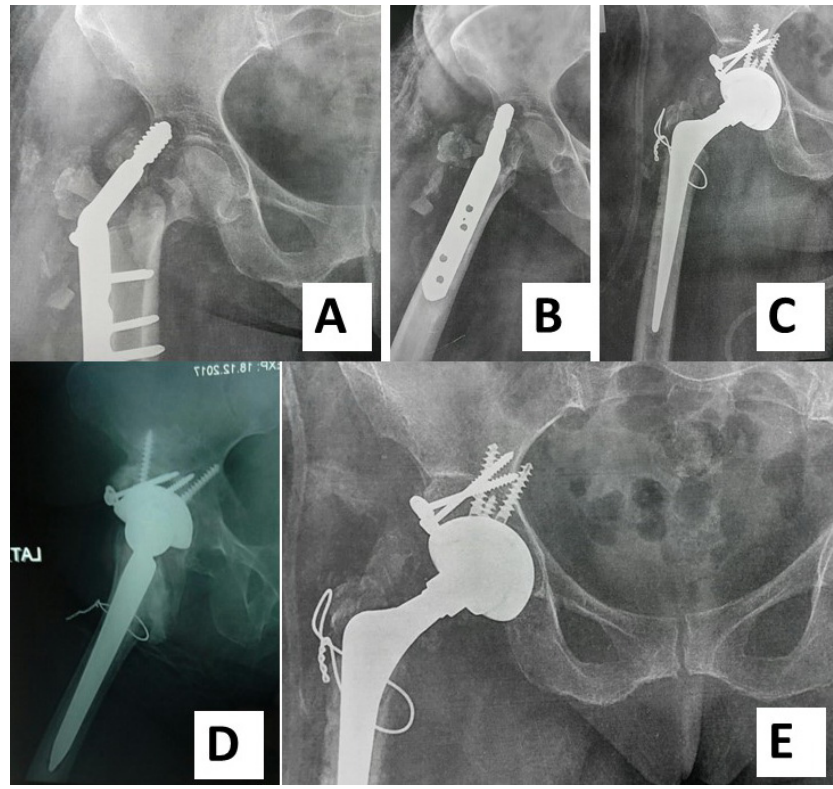

Fig3. Female patient 62 years old (Case No. 11): A\&B) preoperative x-ray with screw penetration and acetabular erosion and segmental defect; C\&D) postoperative $x$-ray with hybrid THR (cementless cup and cemented stem) with acetabular reconstruction with bone graft from the head remnant.

Harris hip score (HHS) [15] was used for clinical evaluation preoperatively, postoperatively and at last follow up The score has a maximum of 100 points (best possible outcome) covering pain (1item,0-44points), function (7items,0-47points), absence of deformity(1item,4points), and range of motion (2items, 5points). The score of (90-100 points) HHS is excellent, good (80-90), fair (70-80), and poor (below 70 points) [16]. Limb length measurement, preoperative clinical examination and, hematological investigations as complete blood count, erythrocyte sedimentation rate (ESR) and C-reactive protein (CRP) were done for all patients regarding occult infections.

Radiographic evaluation comprising AP radiographic views of the pelvis and proximal femur with lateral view of the femur were performed at follow-up visits. Engh et al [17] criteria was used for femoral stems evaluation. Radiolucencies in bone-prosthesis interface was recorded and evaluated according to Gruen et al [18] zonal system. De Lee and Charnley [19] criteria for acetabular evaluation. Acetabular inclination was measured using the interteardrop line as a reference point. Acetabular inclination was considered accepted when between $35^{\circ}$ and $55^{\circ}$. Cementless cup loosening was defined as implant migration, a complete radiolucent line at the implant bone interface, or fixation screws breakage [20]. Heterotopic ossification according to Brooker et al [21] system, and classes III and IV were considered clinically important.

\section{Operative Procedure}

Spinal anesthesia in all operations were used. Hardinage approach in lateral position was performed in all cases. The skin incision included the previous scar in 10 patients and new incision not related to previous scar in 30 patients. To avoid intraoperative femoral shaft fracture, the hip was dislocated before removing the implant in 14 cases. In those 14 cases, the hip was quite stiff and the bone was of poor quality. The implant was removed before dislocation in 10 cases, and in situ neck osteotomy was performed in 8 cases, and the implants 
were extracted in a previous sitting in 8 infected cases. The greater trochanter nonunion was found in twelve patients and stainless steel wire was used for reattachment after insertion of the stem in 6 of them (Fig 3), and ac bond for other 6.In eight patients malunion of greater trochanter was found (five with valgus and three with varus deformity).Five patients had screw cut out, and one of this cases had acetabular defect due to lag screw cut through which was reconstructed using bone graft during the operation (Fig 3). Difficulty inreaming of the femoral canal was found in most cases due to new bone formation, deformity of proximal femur and fibrosis. Flexible reaming on a guide wire to ream the canal was used for femoral preparation. Patients with intramedullary nails had great difficulty in canal reaming due to the old entry and bone sclerosing. Image intensifier was prepared routinely in all cases. Stem selection for patients depended upon available bone quality and stability of trial on table. In four patients, intraoperative fracture extension or new fracture occurred, in four cases calcar replacement stem was used, and augmentation plate fixation in two cases when the fracture was distal to the stem end. Closure of the wound over suction drains which kept in situ for 2 days. Prophylaxis for deep vein thrombosis (DVT) using medical and mechanical methods was done for all patients. Clexane 40 units subcutaneous were used 24 hours preoperative and from $2^{\text {nd }}$ day through 3 weeks postoperative in all patients. Patients stay in hospital ranged from 6 to 15 days. After removal of stitches by 2 weeks regular monthly visits for six months, and every six months up to the end of follow up.

\section{RESULTS}

The mean time of follow up was 48 months (range from $36-72$ months). The operative time ranged from 140 to 225 minutes (Average 165), with a mean blood loss of $1200 \mathrm{ml}$ (range from 800 to $2200 \mathrm{ml}$ ).The minimum follow up period was 3 years. Forty patients only were available at the end of follow up as six patients were lost during follow up. The mean preoperative Harris hip score (HHS) was 24 points with poor score in all patients, and improved significantly to a mean of 88 points (range: 75-96 points) at the latest follow up. At the end of follow up, sixteen patients had excellent results (40\%); fourteen with good results (35\%), eight hips (20\%) with fair results and two hips (5\%) had poor results. When comparing the mean HHS in cases with cemented stem (10 stems) and cases with cementless stem (30) there was no significant difference (Table 2).

Table2. Clinical results and complications.

\begin{tabular}{|c|c|c|c|c|c|c|c|}
\hline \multirow[t]{3}{*}{ Harris hip score } & \multicolumn{2}{|c|}{ Mean score (points) } & \multicolumn{4}{|c|}{ Postoperative score (number of patients \%) } & \\
\hline & Preoperative & Postoperative & Excellent & Good & Fair & Poor & \\
\hline & 24 points & 88 points & $16(40 \%)$ & $14(35 \%)$ & $8(20 \%)$ & $2(5 \%)$ & \\
\hline \multirow[t]{2}{*}{ Complications } & $\begin{array}{l}\text { Postoperative } \\
\text { dislocation }\end{array}$ & \multicolumn{2}{|c|}{ Heterotopic ossification } & \multicolumn{2}{|l|}{ Infection } & Revision & D V T \\
\hline & 2 patients & $\begin{array}{l}\text { Grade II(3 } \\
\text { patients) }\end{array}$ & $\begin{array}{l}\text { Grade } \\
\text { III(1 patient) }\end{array}$ & $\begin{array}{l}\text { Superficial } \\
\text { (3cases) }\end{array}$ & $\begin{array}{l}\text { Deep } \\
\text { (1case) }\end{array}$ & (1 case $)$ & 3 cases \\
\hline
\end{tabular}

Pain relief and gait correction were documented at the final follow up. Limb shortening was detected in ten patients (25\%) and ranged from 15 to $30 \mathrm{~mm}$ (average $22 \mathrm{~mm}$ ). Preoperatively, tenpatients (25\%) had moderate pain with using two crutches for ambulation; twenty one patients (52.5\%) had severe pain and were unable to walk, and nine (22.5\%) had limited walking ability using a walker. Postoperatively, no pain or residual mild pain which did not interfered with daily activities was found in 20 patients (50\%), trochanteric pain in six (15\%), and anterior thigh pain in 12 patients (30\%). In two patients (5\%) moderate to severe pain was found. Postoperative DVT proven by Doppler examination was found in three patients and were treated medically. All patients were able to walk with different walking ability. Thirty patients $(75 \%)$ could freely walk outdoors using a cane or elbow crutch; six patients $(15 \%)$ had a limited walking ability using two axillary crutches, and four patients (10\%) were able to walk indoors only. 
Radiologically, follow up x-rays AP, Lateral views of hip joint with AP view of pelvis were done for all patients every month for 6 months, and every 6 months later tell the final follow up. Postoperative dislocations occurred in two patients (5\%) and closed reduction was done in the two cases (Fig 4). Heterotopic ossification was seen in four $(10 \%)$ of the patients and it was Brooker grade II in three, and grade III in one patientbut this ossification did not lead to ankylosis (Figure 5). The acetabular inclination was within the accepted range 35-55 degrees in 36 hips ( $90 \%$ ), with four cups (10\%) were vertically oriented, and no cup was horizontally oriented. The femoral stem was in neutral position in 32 stems (80 \%), 5 stems (were in $12.5 \%$ ) in varus, and 3 stems $(7.5 \%)$ were in valgus position.

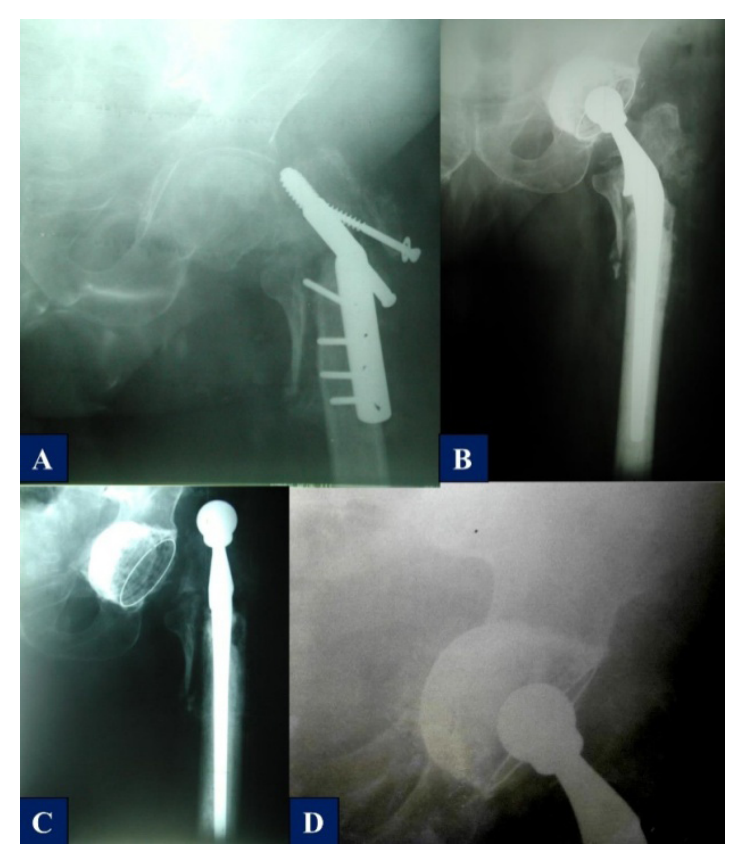

Fig4. Male patient 68 years old (Case No. 18): A) preoperative $x$-ray with implant failure; $B$ ) postoperative $x$-ray with cemented THR; $\boldsymbol{C}$ ) postoperative dislocation 3 weeks postoperative; D) $x$-ray after closed reduction.

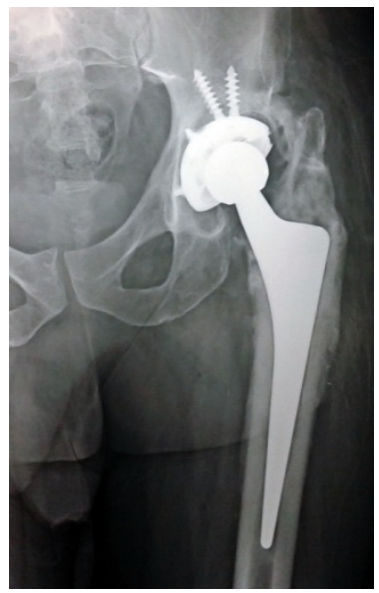

Fig5. X-ray showing hypertrophic ossification grade III (Case No.32).

According to Engh's criteria [17], 26 of 32cementless stems were stable and had bony in growth with no significant subsidence, 5 were stable fibrous, and one stems was loose and infected. This patient had revision at 24 months postoperative with long stem cementless modular prosthesis (Figure 6). Radiolucency of $1 \mathrm{~mm}$ 
of cementless acetabular component was seen in 2 zones in six hips (15\%), (zones $1 \& 2$ in 4 hips, and zones $2 \& 3$ in 2 hips) and these lucencies were not progressive. Two cemented stems with probable loosening at 4 and 6 years, but clinically the patient had minimal discomfort and no revision needed for these two cases. According to Gruen zones criteria [18] for femoral stem, four stems had radiolucent line of 3mm in 2 zones but stems were stable. At the final follow up, all cemented acetabular cups except two were stable. In one patient, the radiolucent line around the cemented cup in 2 zones with cup orientation changed from 45 degrees postoperative to 60 degrees at final follow up, but the patients did not agree revision. Superficial infection was found in three cases treated conservatively by repeated dressings and I V antibiotics. Septic loosening found in one case had two stage revision.

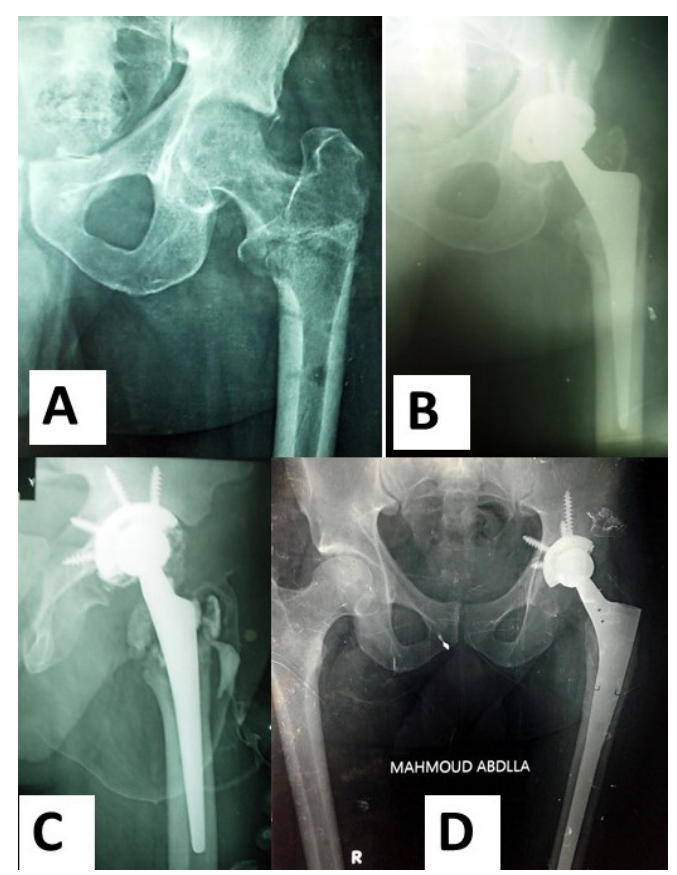

Fig6. Male patient 44 years old (Case No. 32): A) $x$-ray after DCS extraction with nonunion and avascular necrosis of femoral head; $\boldsymbol{B})$ postoperative $x$-ray with cementless $T H R$; $\boldsymbol{C}$ ) $x$-ray 1.5 years postoperative with septic loosening; D) $x$-ray after revision with long stem calcar replacement.

\section{Discussion}

Failed internal fixation of trochanteric fractures of the femur can cause significant pain and functional disability affecting the patient's daily activities. Hip replacement options were used to manage these patients either hemi arthroplasty or total hip replacement. The type of prosthesis can be affected by the patient age, type of implant failure and the bone stock remained after removal of the implant. The method of fixation either cemented or cementless can be determined intraoperative after removal of implants [1, 3, 5, and 22].

Multiple technical difficulties present in these cases as the holes after removal of hardware, malunion and deformity of proximal femur with loss of landmarks, loss of bone stock, regional osteopenia, and soft tissue fibrosis with muscle weakness. Difficulties in canal reaming due to fibrosis, old entry of cephalomedullary nail, new bone formation were found in this series, so the beginning of reaming using flexible reamer over a guide wire under image intensifier was used and in eight cases there were no proximal femoral bone for implant stability, so long cementless stem was used in these cases. In cases with trochanteric nonunion reattachment and stainless steel wire fixation was used in 12 cases [22]. Calcar replacement, fully coated stems were used in four patients in these study due to loss of proximal femoral bone with no support to the standard implant. 
Thakur et al. [23] reported on 15 patients with failed intertrochanteric fractures using hip arthroplasty using a modular distally fixing stem total hip replacement. Harris hip score was improved from 35.9 preoperative to 83 postoperative. They had two patients (13.3\%) walking without aid, $10(66.7 \%)$ using a cane and $3(20 \%)$ using a walker for ambulation. They had no patients with dislocation, DVT in one patient (6.67\%), and heterotopic ossification in seven patients; 5 patients Brooker's grade (1) and 2 patients grade (2). They used constrained liner in two patients due to questionable stability of the hip intraoperative.

In the study of Haidukewych and Berry [4], there were sixty patients of failed internal fixation treated with hip arthroplasty, 32 total hip replacements and 28 hemiarthroplasty. They reported 39 (89\%) of survived 44 patients had mild or no pain after a mean follow up period of 65 months. There were $91 \%$ of their patients able to walk; and 59\% using arm support.

Zhang et al. [24] evaluated the results of arthroplasty in 19 cases with 14 cemented 3 cement less, and 2 hybrid hip replacement after failed internal fixation of intertrochanteric fractures and they reported $47 \%$ incidence of complications with $31 \%$ intraoperative fracture and $16 \%$ postoperative dislocation. Clinically, the mean Harris hip score after follow up of 2 years was 79.8 .

The decision using total hip replacement in this work was due to acetabular damage either due to screw penetration, chondrolysis, or present osteoarthritis. The selection of cemented or uncemented stem was according to bone stock remained and stability of stem in press fit during reaming. Long stem was used when trochanteric area was comminuted and prosthesis not contained in proximal calcar part.

In this work, good results may be due to the relative young age of patients and the selection of the suitable technique for the right patient. The survival rate in6 years were $95 \%$ as two patients required revision. Dislocation rate was $5 \%$ in this series, closed reduction was done in both cases. The Harris hip score improved from 24 preoperative to 88 postoperative with no or mild residual pain in 18 patients (45\%), trochanteric pain in six (15\%), and anterior thigh pain in 14 patients (35\%). In two patients (5\%) sever pain was found, in one patient septic loosening and revision was done at 24 months postoperative (Figure 6), the other one had aseptic loosening but refused revision.

\section{CONCLUSION}

Total hip arthroplasty is a good salvage procedure after failed internal fixation of trochanteric femoral fractures. Individual selection of the implant depends upon the age of patient, level of activity, the bone stock of proximal femur, and the condition of the acetabulum. To maintain stability, reattachment of the greater trochanter should be done. To avoid intraoperative fractures of osteoporotic bone, dislocation of the hip should be very careful.

\section{REFERENCES}

1. Gotfried Y, Cohen B, Rotem A. Biomechanical evaluation of the percutaneous compression plating system for hip fractures. J Orthop Trauma. 2002; 16:644-50.

2. Ruecker AH, Rupprecht M, Gruber M, Gebauer M, Barvencik F, Briem D. The treatment of intertrochanteric fractures: results using an intramedullary nail with integrated cephalocervical screws and linear compression. J Orthop Trauma. 2009; 23:22-30.

3. Wu CC, Shih $\mathrm{CH}$, Chen WJ, Tai CL. Treatment of cutout of a lag screw of a dynamic hip screw in an intertrochanteric fracture. Arch Orthop Trauma Surg 1998; 117:193-6.

4. Haidukewych G J; Daniel B J. Hip Arthroplasty for Salvage of Failed Treatment of Intertrochanteric Hip Fractures, J Bone Joint Surg 2003; A, 85 (5): 899 -904. 
5. Alvarez DB, Aparicio JP, Fernández EL, Múgica IG, Batalla DN, Jiménez JP. Implant breakage, a rare complication with the gamma nail. A review of 843 fractures of the proximal femur treated with a gamma nail. ActaOrthopBelg 2004; 70:435-43.

6. Anglen JO. Intertrochanteric osteotomy for failed internal fixation of femoral neck fracture. Clin Orthop Relat Res. 1997; 341:175-82.

7. Said GZ, Farouk O, El-Sayed A, Said HG. Salvage of failed dynamic hip screw fixation of intertrochanteric fractures. Injury. 2006; 37:194-202.

8. Javahir A P, Vikram I.S, Ashish N S, Kalpesh P S, Dhiraj P M, Rahul P. Hip arthroplasty in failed intertrochanteric fractures in elderly; Indian J Orthop. 2013; Vol: 47(6) P: 572-577.

9. Syed S. N.; Mehroze Z.; and Muhammad K. R. N. Total Hip Arthroplasty in Failed Hip Fractures: A Case Series; Reconstructive Review. 2015; Vol. 4, No. 4, Dec 2014.

10. Haentjens P, Casteleyn PP, Opdecam P. Hip arthroplasty for failed internal fixation of intertrochanteric and subtrochanteric fractures in the elderly patient. Arch Orthop Trauma Surg, 1994; 113: 222-7.

11. Goldstein WM, Branson JJ. Modular femoral component for conversion of previous hip surgery in total hip arthroplasty. Orthopedics. 2005; 28 Suppl 9:s1079-84.

12. Laffosse JM, Molinier F, Tricoire JL, Bonnevialle N, Chiron P, and Puget J. Cementless modular hip arthroplasty as a salvage operation for failed internal fixation of trochanteric fractures in elderly patients. ActaOrthopBelg 2007; 73:729-36.

13. Mears DC, Durbhakula SM, Velyvis JH. Reconstructive total hip replacement after proximal femoral injuries. In: Browner BD, Jupiter JB, Levine AM, Trafton PG, editors. Skeletal Trauma. Philadelphia, PA.; Saunders. 2003; p. 1817.

14. Patterson BM, Salvati EA, Huo MH. Total hip arthroplasty for complications of intertrochanteric fracture. A technical note. J Bone Joint Surg. 1990; 72A: 776-777.

15. Harris WH. Traumatic arthritis of the hip after dislocation and acetabular fracture: treatment by mold arthroplasty. J Bone Joint Surg; 1969.51A: 737-755.

16. Anna N and Ann B (2011): Measures of Hip Function and Symptoms; Arthritis Care \& Research Vol. 63(S11), pp S200-S207.

17. Engh CA, Bobyn JD, Glassman AH.: Porous coated hip replacement. The factors governing bone ingrowth, stress shielding, and clinical results. J Bone Joint Surg. 1987; 69B; 45-55.

18. Gruen TA, McNeice GM, Amstutz HC: Modes of failure" of cemented stem-type femoral components: a radiographic analysis of loosening. Clin Orthop. 1979; 141:17.

19. DeLee, J. G., and Charnley, J. Radiological demarcation of cemented sockets in total hip replacement. Clin. Orthop.1976; 121:20-32.

20. Brinker MR, Rosenberg AG, Kull L. Primary noncemented total hip arthroplasty in patients with ankylosing spondylitis, clinical and radiographic results at an average follow-up period of 6 years. J Arthroplasty 1996; 11:802.

21. Brooker AF, Bowerman JW, Robinson RA: Ectopic ossification following total hip replacement. Incidence and a method of classification. J Bone Joint Surg 1973; 55A: 1629-1632. 
Salvage Total Hip Replacement after Failed Internal Fixation of Trochanteric Fracture Femur

22. Xiaojun S, Zongke Z, Jing Y, Bin S, Pengde K, and Fuxing P. Total Hip Arthroplasty Using Non-Modular Cementless Long-Stem Distal Fixation for Salvage of Failed Internal Fixation of Intertrochanteric Fracture; J of Arthroplasty. 2015; Vol 30, (11), P: 1999-2003.

23. Thakur RR, Deshmukh AJ, Goyal A, Ranawat AS, Rasquinha VJ, Rodriguez JA. Management of failed trochanteric fracture fixation with cementless modular hip arthroplasty using a distally fixing stem. J Arthroplasty 2011; 26:398-403.

24. Zhang B, Chiu KY, Wang M. Hip arthroplasty for failed internal fixation of intertrochanteric fractures. J Arthroplasty 2004; 19:329-33.

Citation: Mohammed a Elhenawy. "Salvage Total Hip Replacement after Failed Internal Fixation of Trochanteric Fracture Femur". American Research Journal of Orthopedics and Traumatology. 2018; 3(1): 1-10.

Copyright (c) 2018 Mohammed a Elhenawy. This is an open access article distributed under the Creative Commons Attribution License, which permits unrestricted use, distribution, and reproduction in any medium, provided the original work is properly cited. 